Bianca Rihan Pinheiro Amorim:

\title{
Produção informacional na era do capitalismo neoliberal: uma crítica ética e dialética
}

\begin{abstract}
:
This article discusses an ethical conception for informational production based on historical-dialectical materialism. Starting from the notion of ethics as a critical attitude towards hegemonic morality, we will make use of the categories of totality and historicity to formulate a critical argument for information submitted to the control of capital and as an instrument for the creation of a "morality" based on the values of the ruling class, both in the sphere of epistemological production, and in the economic and media spheres in times of neoliberal globalization. However, as a historical product, it also seems essential to present the information from the intervention of the human being in the world and, therefore, in permanent movement and dispute, being able to become an effective pillar for the ethical-political project of human emancipation, or the good in a universal sense of fact.
\end{abstract}

\section{Resumo:}

O presente artigo discute uma concepção ética para a produção informacional baseada no materialismo histórico-dialético. Partindo da noção de ética como atitude crítica diante da moral hegemônica, faremos uso das categorias de totalidade e historicidade para formularmos argumento crítico à informação submetida ao controle do capital, e enquanto instrumento para a criação de uma "moral" baseada nos valores da classe dominante, tanto na esfera da produção epistemológica, como nas esferas econômica e midiática em tempos de globalização neoliberal. Porém, como produto histórico, parece-nos também imprescindível apresentar a informação a partir da intervenção do ser humano no mundo e, por isso, em permanente movimento e disputa, podendo converter-se em um efetivo pilar para o projeto ético-político da emancipação humana, ou para a produção do bem em sentido universal de fato.

\section{Agenda:}

Ética, totalidade e historicidade

Uma crítica dialética à neutralidade axiológica dos estudos informacionais na sociedade de classe

A informação em tempos de globalização neoliberal ............................................................ 45

Informação, ética e liberdade: ou uma conclusão de esperança.............................................. 48

Author:

\section{Bianca Rihan Pinheiro Amorim}

- PhD graduate student at Universidade Federal do Rio de Janeiro, IBICT, Lauro Müler 445 - Botafogo, Rio de Janeiro.

- 疋 + 55 - 21 - $999563652 \square$ bibirihan@gmail.com 
- Relevant publications:

- AMORIM, Bianca; SALDANHA, Gustavo. A Ciência da Informação entre os feitiços dos centros de ciência e os antídotos dos laboratórios da vida. Perspectiva em Ciência da Informação. V.9, n. 2, 2016.

- AMORIM, Bianca; SALDANHA, Gustavo. Dispositivos de Informação e Comunicação: o lugar dos murais zapatistas na construção da autonomia chiapaneca. 3èmes journées scientifiques intenationales du Réseau Franco-Brésilien de chercheus en Médiations et Usages Sociaux des Savoirs et de Information (MUSSI), 2016, Toulouse. De la médiation de savoirs: science de Information-documentation et mémoires, 2016. 


\section{Ética, totalidade e historicidade} A objetividade dos valores está baseada no fato de que eles são partes moventes e movidas do
desenvolvimento social

G. Lukács

Comecemos a falar de ética que, por tantas vezes, no terreno das cotidianidades, é usada como conceito sinônimo de moral. Apesar de reconhecermos certo bom senso na indução do uso dos termos a partir da similitude de seus significados, cabe diferenciá-los enquanto conceitos.

Ética, em sua etimologia, vem do grego ethos, podendo ser traduzida como hábitos, costumes, modos de ser; já moral, deriva da palavra latina mores, que também aponta para algo como costumes. Logo, os campos da moral e da ética são comumente evocados para fazer relação a conjunto de valores, regras e normas que orientam os indivíduos.

Porém, como ressalta Sodré (1995, p.51), há uma significação diferente para a ética, derivada de um outro e antiquíssimo ethos (que aparece no grego com eta longo), designando o ato de morar, ou a organização de um grupo de indivíduos em um determinado lugar em busca do supremo para a comunidade, ou seja, de seu bem. Em Heráclito, essa ideia aparece no fragmento "ethos anthropos daimon", traduzido como "O caráter do homem é seu deus ou seu demônio", ou "Deus é a morada do homem".

Também em Aristóteles, em sua "Ética a Nicômaco", percebemos a ética como teoria conduzida a interpelar os fundamentos da prática especificamente humana, que devem ser determinados pelo bem; ou seja, "a ética como lugar ontológico do homem, e o bem como ponto para onde convergem todas as forças de ordenamento ou de ação certa para a comunidade" (SODRÉ, 1995, p. 53).

Para Sodré, a não observância de tal distinção - entre a universalidade de fato e a universalidade de direito - é que coroa, na modernidade, um sentido limitado para a ética (segundo a tradução latina), obediente aos regulamentos institucionais ou às corporações profissionais. Ao passo que pensar a ética em sua ideia original, deveria incorporar uma atitude desviante da autoridade de um saber estabelecido ou de um poder técnico sobre o mundo, e aproximar-se cada vez mais das perguntas, do vigor da procura, da liberdade: " $A$ 'theoria' ética resulta da esfera da liberdade, das escolhas de modos cada vez mais atualizados de se por em relação com o outro" (BATISTA, 1995, p.41).

Assim, tomamos como certeiras as considerações de Rios (2006, p. 81) quando defende que "é de acordo com a moral que se diz: faça isso; não faça aquilo". Contudo, somente quando procuramos questionar os valores que sustentam a moral, quando buscamos seus fundamentos, é que entramos no terreno da ética. "A ética pode, então, ser definida como uma atitude crítica diante da moralidade, uma investigação sobre a consistência e o significado dos valores morais".

Resgatando E.P. Thompson (2001), um dos autores mais atentos às normas, aos valores, ao conjunto de elementos morais presentes em uma sociedade - e ao aumento significativo que o estudo desse conjunto pode propiciar ao conhecimento sobre tal sociedade - explicitamos, assim como ele, a necessidade fundamental de situarmos esses elementos em seus contextos históricos, assim como localizarmos os diversos ângulos sob os quais se apresentam, e o relacionarmos às tantas variáveis que os produzem e os mantêm.

Seguindo a linha de raciocínio thompsoniana, devemos estar atentos para a necessidade de os significados das regras e normas sociais, ou os significados da moral hegemônica em determinados períodos históricos, serem sempre contextualizados, assim como priorizadas as relações reais que neles se expressam, afinal: 
Todo significado é um significado no contexto, e, quando as estruturas mudam, as formas antigas podem expressar funções novas $e$ as funções antigas podem encontrar sua expressão em novas formas (THOMPSON, 2001, p. 238)

Portanto, se devemos chamar a atenção para o fato de que a vida social produz valores e regras morais, que informam o indivíduo e contribuem para suas ações e decisões, importa também relembrarmos que eles não são universais de fato e nem sempre representarão o bem. Ou seja: não confundamos moral e ética.

Partindo da inspiração acima, sublinhamos que a noção de ética aqui defendida fundamenta-se na razão dialética, ou em um todo orgânico, sempre em movimento e atravessado por conflitos, pois é a partir de uma visão da totalidade - considerando os contextos econômico, político e cultural -, e da historicidade das partes em conflito reclamando o bem, que poderemos observar a universalidade de fato (como sublinhado por Sodré).

Em outros termos, trata-se de travarmos uma crítica radical ao conjunto de valores hegemônicos - da moral hegemônica em nossa sociedade de classe - partindo das categorias de totalidade e historicidade para apreendermos o real.

Nesse sentido, buscaremos debater a utopia da sociedade informacional, que pautada pela retórica tecnocientífica, construtora da ideia de informação como "objeto" neutro, e por discursos midiáticos moralizantes (leia-se, formadores de valores), direcionados pela visão de mundo das classes dominantes, afastou-se da ética e do "bem", no sentido da "vida em liberdade" (SODRÉ,1995, p.56), para torna-se um importante instrumento de implementação moral do capitalismo financeiro e da globalização neoliberal ao redor do mundo, onde o "bem" é garantido apenas para uma parte privilegiada do todo.

\section{Uma crítica dialética à neutralidade axiológica dos estudos informacionais na sociedade de classe}

Contemporaneamente, as novas tecnologias digitais avançam com grande velocidade, influenciando de maneira decisiva todos os âmbitos da vida humana (CAPURRO, 2015, p.13). Como ressalta Schneider (2015), não é pouco o peso dos fluxos informacionais, em especial aqueles midiatizados, na construção de valores, gostos e da moral hegemônica em nosso tempo.

A grande euforia quanto às benesses da chamada sociedade da informação ganhou eco em meados da década de 1950, época atravessada pelas significativas transformações decorrentes da II Guerra Mundial (1939-1945), e pela ideia de que os avanços tecnológicos, a partir dali conquistados, poderiam resolver boa parte dos impasses e problemas da humanidade.

Assim, o repertório retórico dos estudos informacionais passou a alardear a prontidão dos novos sistemas tecnológicos de informação em responder às demandas de modernização e reconstrução dos Estados e das sociedades, assim como defender a objetividade e leis universais conformadoras de padrões de regularidade e progresso para a informação, tal qual sugerem os modelos matemáticos (teoria da informação), físicos (entropia) ou biológicos (teoria epidemiológica).

Claramente, tal manifestação indica grande influência do movimento sócio-histórico que pautou o positivismo como principal expressão da razão moderna e, logo, como suporte teórico e metodológico privilegiado para justificar a produção de conhecimento e, também, para apreender a informação.

Como na definição das leis sociais, todas as categorias desse modelo de apreensão informacional representadas, dentre outras, pela bibliometria, cienciometria, informetria e webometria - constituem-se intimamente relacionadas aos princípios positivistas e à análise pura dos objetos investigados, ou seja, à procura de uma precisão que conduz a previsões de comportamento, como no desiderato comtiano "ver para prever" (BEZERRA, SALDANHA, 2013, p. 44). 
Da cibernética de Wiener (1947), passando pela teoria da informação de Shannon e Weaver (1948) e pela teoria geral dos sistemas de Bertalanffy (1951), a utilização de sociogramas para o mapeamento dos fluxos de informação, a aplicação de questionários a grandes amostras de usuários, e a busca de invariantes cognitivos para a construção de sistemas de informação são apenas alguns exemplos das abordagens que olham para a realidade social a partir de perspectiva puramente estatística e quantitativa (ARAÚJO, 2003, p. 24). 0 efeito dessas concepções é o alijamento entre informação e sujeitos, tratados apenas como cognoscentes, portanto isolados dos condicionamentos sociais e materiais, próprios ao existir humano (CAPURRO, 2003).

Por tudo isso, como bem ressalta Capurro (2003), é urgente combatermos a ideia de informação como representação/ duplicação, uma vez que sua existência é, antes, a relação dialética entre sujeitos e um vasto complexo material e simbólico. Isso quer dizer que a informação, e também sua produção epistemológica, não acontecem em uma dimensão etérea, que paira democraticamente em um espaço neutro, sendo essa "uma ficção interessada que permite aparentar como científica uma forma neutralizada e eufêmica (simbolicamente muito eficaz porque irreconhecível) da reprodução dominante do mundo social (BOURDIEU, 1994, p. 142)".

Nesse sentido, a produção do italiano Antonio Gramsci (1987) se torna um interessante instrumento para pensarmos criticamente a informação e a sua produção epistemológica, uma vez que sua obra nos inspira uma concepção de análise da realidade baseada na totalidade e na historicidade. Negando esquemas classificatórios que reduzam o econômico especificamente à infraestrutura e os demais "domínios" da sociedade - o político, o cultural ou o ideológico - ao espaço superestrutural - de reflexo; mas por outro lado enfatizando, sempre, a conexão profunda entre a história das ideias e o desenvolvimento das forças produtivas, o autor destaca como os discursos (e aqui apontamos para o discurso científico) podem ser considerados como uma das dimensões organizativas das classes e do próprio Estado (MENDONÇA, 1996), na medida em que ajudam a formular e a legitimar uma gama de exigências, normas e ideias a serem seguidas pela sociedade em geral.

Ao atualizar a noção de Estado a partir da categoria de "Estado ampliado", ou seja, tomando o Estado não apenas a partir da sociedade política [estrito senso], mas considerando as pressões e contrapressões entre sociedade política e sociedade civil na luta pela hegemonia na direção do Estado (MENDONÇA 1996), Gramsci certamente concordaria com a inclusão do campo científico em uma dessas frentes de disputa entre classes/frações de classe. A partir da ciência, a luta de classes torna-se também luta de classificações. E, ao passo que os discursos científicos são defendidos pelos "autorizados" do campo científico como orientados para o bem comum sua força de consenso amplia-se de maneira brutal.

Ao estabelecer um conjunto de "verdades universais" / "regras morais universais" a partir da ciência, quando essas estão, na realidade, diretamente imbricadas aos interesses econômicos, político e culturais de determinadas classes/frações de classe, a ciência autoproclamada como "pura" está, além de produzindo conhecimento ${ }^{1}$, reproduzindo ideologias e garantindo orientações morais classistas para o Estado, o que muito se afasta de uma concepção de ética pautada pelo bem universal de fato.

Logo, é a universalização de interesses particulares - e de uma moral particular - que explica a ocultação do caráter de classe do Estado, assim como o silenciamento das lutas de classe e classificação que inundam seus inúmeros campos de reprodução, como o campo científico.

Como bem destaca Mészáros (2004), a produção científica não pode ser descolada de sua relação limiar com o complexo geral do desenvolvimento capitalista. Devendo, portanto, ser examinada à luz das contradições

1 Como também destaca Mészáros, é importante reconhecermos um certo aspecto relativamente autônomo do desenvolvimento científico, cuidando porém para não tornar absoluta a lógica da autonomia no desenvolvimento científico ao desconsiderar as determinações sócio-históricas, como é costumeiro no processo de reprodução da ideologia dominante (Mészáros, 2004). 
que caracterizam as práticas produtivas capitalistas em sua totalidade. Logo, nenhuma posição privilegiada deve ser atribuída a uma ciência idealizada ou "neutra":

Como as formas e práticas existentes da ciência eram manifestações também da alienação e da divisão do trabalho prevalecentes, todo o complexo tinha de ser radicalmente questionado, em todos os aspectos, caso se quisesse explicar como as imensas potencialidades criativas das tendências em desenvolvimento foram transformadas - inclusive no da ciência - em realidades destrutivas pelas contradições estruturais do capital (MÉSZÁROS, 2004, p. 248).

Segundo o autor, desde a formulação das doutrinas de Auguste Comte e seus seguidores, o "positivismo acrítico" tratou de interditar qualquer debate quanto à dimensão histórica da visão de mundo dos dominantes. De modo que o grande sucesso do positivismo (e do neopositivismo) desde então se relaciona mais a este esmagamento radical da dimensão histórica do que a qualquer outra coisa. Assim, a autoridade da ciência para Mészáros uma caricatura da ciência, definida como um constructo inteiramente anistórico - foi utilizado para disfarçar a substância social altamente conservadora dos pontos de vista defendidos.

Outra seara de grande valia às pesquisas recentes sobre a epistemologia, colocada por Mészáros, trata-se da problematização da ideia de "progresso científico", que ainda hoje se fortalece nos trilhos e desdobramentos do positivismo "combatente" da dimensão histórica e crítica da teoria social. Negligenciando a dinâmica historicamente manifesta dos processos e contradições sociais objetivos, passa-se a evocar uma "temporalidade abstrata", baseada na pretensão autorreferente de um suposto progresso linear da ciência, porém, estreitamente associada aos modos de produção e acumulação capitalista.

Com a introdução da ciência (interpretada de modo positivista) na concepção geral, uma nova relação de identidade poderia ser estipulada. Tratava-se da identidade entre o "progresso" - representado como "progresso científico" - e o próprio modo de produção capitalista, porque imaginava-se este último não somente como o equivalente produtivo ideal das determinações naturais originadas diretamente das necessidades básicas, mas também como a única incorporação adequada do "espírito científico" como tal e dos benefícios "evidentes que ele proporcionaria às pessoas da "sociedade industrial moderna" - Isto é, da sociedade que realmente correspondia às exigências internas desse espírito científico" um tanto mítico (MÉZÁROS, 2014, p. 253).

Nos estudos informacionais hegemônicos, sobretudo na área do conhecimento institucionalizada, designada Ciência da Informação, a ideia de progresso é apresentada como resultante da técnica aliada às novas tecnologias, o que definiria uma ciência dinâmica e moderna. Por sua vez, o diálogo com as ciências sociais contribui para garantir as possibilidades de sua originalidade, elevando a validação e reconhecimento da CI entre os pares e o senso comum (BEZERRA, SCHNEIDER e CASTRO, 2015).

Porém, apesar dos discursos sobre a interdisciplinaridade e a própria classificação da área enquanto ciência social aplicada, permanece um grande déficit acerca do "social", e o quase nulo questionamento sobre as ideologias ${ }^{2}$ contidas nos seus "aparatos classificatórios, cientométricos e bibliométricos", tidos até hoje como instrumentais inquestionáveis.

Para nós é clarividente que o dito "progresso" encontra-se orientado para a lógica desenvolvimentista e mercadológica, que parece responder às pressões inscritas na ordem do Estado ampliado e da globalização 
neoliberal, cerceando os objetos de pesquisa e promovendo uma espécie de unificação teórica e metodológica para a abordagem informacional.

A pressão por produtividade e por uma maior contribuição ao desenvolvimento e ao crescimento econômico [...]o que implica também uma maior permeabilidade às demandas (tecnológicas, inclusive mão de obra qualificada) do capital privado - pressões em geral localizadas no próprio aparelho de Estado, que se materializam muito claramente na (permanente) ameaça de desfinanciamento, expressão eloquente, quase obscena, da intimidade nem sempre aparente entre a dominação econômica e a simbólica (BEZERRA, SCHNEIDER e CASTRO, 2015, p. 61).

Tal análise, sobre a produção epistemológica informacional em uma sociedade de classe, fornecerá algumas pistas de como a informação tecnológica "defendida" para toda a sociedade a partir de um discurso técnico e instrumental torna-se um grande aliado para colocar em marcha a valorização do capital em escala global, sobretudo em tempos de "desmoronamento" de fronteiras ou da chamada globalização neoliberal. A informação supostamente "neutra" mobilizada por um grupo de "experts" ajuda a construir o que Bourdieu (2002, p. 15) chama de lugares-comuns, no sentido aristotélico, ou ideias de verdade e de bem comum, "sob os quais se argumenta, mas sobre os quais não se argumenta".

\section{A informação em tempos de globalização neoliberal}

Em sua aclamada obra "Era dos Extremos", o historiador Eric Hobsbawm nos conta sobre o tabu de quase meio século sobre o uso do termo "depressão", mesmo que a tão alardeada estabilidade do pós-guerra estivesse praticamente em ruínas a partir da década de 1970 . Assim, foi enfático ao afirmar que "a história vinte anos após 1973 é a de um mundo que perdeu suas referências e resvalou para a instabilidade e a crise. No entanto, até a década de 1980 não estava claro como as fundações da Era de Ouro haviam desmoronado irrecuperavelmente" (1995, p. 393).

Entre outras esferas, a crise repercutiu na articulação da burguesia internacional para manter suas bases de sustentação e garantir hegemonia na direção global. Com as justificativas pautadas no enxugamento dos Estados, as políticas de bem estar social foram paulatinamente abandonadas para que o programa neoliberal passasse a dar as cartas, sobretudo a partir do ciclo de privatizações e desregulamentação dos serviços públicos. Com o coroamento das leis de mercado como sistema regulador da economia mundial, os interesses das classes dominantes em escala transnacional - ou do bloco histórico hegemônico - descortinaram a precariedade dos sistemas políticos e institucionais anteriores, assim como precipitaram a gritante desigualdade social ao redor do mundo.

Segundo Hobsbawm (1995, p.413), organizações cujo campo de ação era efetivamente limitado pelas fronteiras territoriais saíam de cena para a entrada catastrófica de organizações não limitadas, como empresas transnacionais, o mercado de moeda internacional e os meios de comunicação e informação. Enquanto se intensificava a corrida global por custos mais baixos de produção, levando espoliação, sobretudo, aos trabalhadores de países periféricos, os Estado nacionais eram solapados pelo desmonte de atividades até então exercidas por órgãos públicos, deixando a vida das pessoas à mercê das vontades do mercado.

Como detalha Demuner (2017, p.16)

O caminho traçado pelas elites político-econômicas para a retomada do crescimento da taxa de lucros foi um conjunto de medidas econômicas e políticas conhecido como neoliberalismo. Este modelo foi, e ainda é, o responsável pela eliminação mundial de todas as barreiras sobre a expansão das forças de mercado, o que significou a formação de um novo projeto de desenvolvimento capaz de reorganizar material $e$ ideologicamente o espaço de produção capitalista, que iniciado minimamente no final dos anos 60 se consolida no decorrer dos anos 80, e na década de 90 assume total liderança nas forças sociais globais. [...] No caso da América Latina, o Consenso de Washington representa bem qual é o caminho colocado pelo capital transnacional à região. O início deste processo é verificado por Cox como a "internacionalização 
da produção" (COX, 1981, p.) em que a transnacionalização do capital ocorre em larga escala com a expansão de multinacionais na cadeia produtiva internacional através do financiamento de bancos privados, as quais fragmentam o processo de produção e se movem para a região do Sul Global em busca dos recursos proporcionados pelos Estados periféricos: mercado consumidor, mão-de-obra, matéria-prima, além de impostos inferiores.

Assim, observamos as artimanhas do capital para se expandir em seu processo de financeirização que, para o autor, atua em via de mão dupla a partir do rentismo/especulação dos organismos financeiros internacionais e da precarização da força de trabalho, principalmente nos países periféricos.

O discurso da globalização enquanto fenômeno inevitável dos elevados fluxos de capital e comunicação serve para legitimar as práticas neoliberais voltadas para a abertura dos mercados nacionais e a ausência declarada dos Estados na administração de setores sociais e públicos. Deste modo, entendendo a relação nodal das forças locais e globais na formação da realidade doméstica (Estado) e internacional (Ordem Mundial) no desenvolvimento desigual e combinado da globalização, é possível percebermos qual classe mais se beneficia/prejudica com as políticas adotadas e os principais mecanismos nas relações internacionais e nacionais adotados neste processo. As classes "(...) possuem suas origens em sociedades nacionais, mas formam links entre as fronteiras que separam as sociedades nacionais" (COX, 1987, p. 357).

A Classe Capitalista Transnacional e as Organizações Internacionais (OIs) - principalmente as econômicas - estiveram inter-relacionadas e ativas diretamente na construção deste bloco histórico que se formava (DEMUNER, 2017, p.17).

Nesse contexto, um fator decisivo para a virada no "controle mundial" por um capitalismo de tipo neoliberal, trata-se do protagonismo ainda maior das chamadas novas tecnologias de informação e comunicação (TICs), que naquele momento foram diretamente associadas ao aumento de fluxos monetários entre as já tímidas fronteiras estatais. Os espaços da organização econômica mundial, em que acontecem as relações de produção, deixam de responder aos "limites" territoriais dos Estados, ao passo que as TICs precipitam-se como ferramentas exemplares para o encurtamento de distâncias e para a internacionalização de capitais em transações dinâmicas e acumulação de grande porte, sem os pesados ativos que, outrora, se constituíam como empecilhos a sua rentabilidade.

Fazendo alusão a Marx, David Harvey exemplifica a questão de como o capitalismo sente-se impelido a "aniquilar o espaço por meio do tempo" e como, nesse movimento, a redução do custo e do deslocamento no espaço tem sido um foco contínuo de inovação tecnológica e informacional (HARVEY, 2004). Ou, como explica Moraes (2002), o capital precisa de grande fluidez para se deslocar mundo afora, portanto, os sucessivos e empolgados discursos da mídia global sobre os feitos extraordinários da era eletrônica e das novas tecnologias de comunicação e informação fazem todo o sentido. O agravante é que, "na era da revolução digital" sob a outorga do neoliberalismo, as possibilidades de beneficiar-se da "incrível velocidade" das novas tecnologias de informação e comunicação ficam praticamente restritas às grandes empresas e corporações que controlam e agenciam a grande maioria da população e, à custa dela, multiplicam seu poder de acumulação.

Vale ainda ressaltar que, desde o fim da década de 1970, podem ser observadas as diretrizes de organismos multilaterais, como o Banco Mundial e o FMI, descaradamente atrelados às necessidades do capital em se reconfigurar, pautando não apenas o modelo econômico a ser seguido, mas também o exemplo de linha política a ser adotada em escala intercontinental. A cartilha das organizações financeiras foi paulatinamente imposta em todas as partes do mundo, com o mercado assumindo a função de regulador das demandas coletivas e o seu discurso, a partir da indústria cultural e da informação globalmente massificada, ganhando ares absolutos e incontestes em detrimento dos diferentes costumes locais, dos laços de solidariedade e da produção do comum.

Conforme Arantes (2006, p. 63) 
A geopolítica mundial se assenta, desde o fim da Segunda Guerra Mundial em instituições globais que definem paradigmas para a gestão monetária, do desenvolvimento e do comércio - o Fundo Monetário Internacional (FMI, o Banco Mundial e o Gatt (posteriormente Organização Mundial do Comércio - OMC). Foram elas que lançaram, ao mesmo tempo em que caíam as bombas nucleares, as bases do novo regime internacional sob hegemonia norte-americana. Do nascimento, na conferência de Bretton Woods, às manifestações de Seattle - as quais iniciaram o movimento mundial antiglobalização, em 1999 - o poder das três instituições pareceu inquestionável. Associadas a elas estão uma dezena de outras instituições internacionais e regionais, como o Banco Interamericano de Desenvolvimento, o BID, fundado em 1959. Elas modelaram durante décadas as políticas econômicas e sociais do chamado terceiro mundo. [...] Sua permanência no tempo, mesmo acabada a Guerra Fria, deve-se à forma como souberam exercer seu domínio - uma hegemonia na qual a coerção se constrói pela dependência financeira e o consentimento pela "racionalidade" de um discurso que se pretende técnico-científico.

Assim, a retórica "respaldada" da globalização vem fortalecendo a imagem de que somente o mercado seja capaz de prover a chamada "organização societária". E tanto os discursos científicos quanto a mídia privada, produtora de uma informação de classe, ao construírem os aparatos de sustentação ideológica para a reprodução ampliada do capitalismo na esfera social global estão, em outras palavras, fabricando "o consenso de que não há alternativa fora dos pressupostos neoliberais", ou "o consenso sobre a superioridade das economias abertas e globalizadas" e de seus serviços para a população (MORAES, 2002, p.8).

Não raro, sem querermos ou pensarmos somos inundados pelo "pensamento único" - feliz expressão de Ignacio Ramonet para designar a matriz ideológica que subordina os direitos sociais dos cidadãos à razão competitiva dos mercados financeiros' - oculta, intencionalmente, a carga atômica de desigualdades e exclusões. Ao mesmo tempo em que reverberam o que Pierre Bourdieu define como "a doxa invasiva e insinuante do neoliberalismo", os conglomerados de mídia atuam como agentes econômicos globais. Segundo o banco de investimentos Veronis Suhler, as indústrias de informação e diversão foram o setor de crescimento mais rápido da economia norte-americana entre 1994 e 2000 - à frente dos mercados financeiro e de serviços. [...] A grande mídia assim opera tanto por adesão ideológica à globalização, quanto por deter a capacidade única de interconectar o planeta, através de satélites, cabos de fibra óptica e redes infoeletrônicas.

Ao longo de uma história regida pela luta de classes, trata-se de não deixarmos de observar a informação, tanto inscrita em uma perspectiva tecno-científica quanto midiática, permanentemente concentrada sob a hegemonia do capital, que controla cotidianamente a sua produção, distribuição e acesso.

Como ressalta Dantas (2000), a informação é algo essencial à produção e realização da vida, mas comandada pelos objetivos de acumulação torna-se centralizada, hierarquizada, verticalizada e mercantilizada. Ou melhor, torna-se uma informação de classe, porque privadamente capturada, apropriada e utilizada. Essa observação possui uma grande importância metodológica ética e política, na medida em que constata a informação como lócus de produção de valor, além de deslindar a dimensão ideológica dos discursos científicos e midiáticos apresentados como "verdades factuais" (SCHNEIDER 2015).

$\mathrm{Na}$ atualidade as próprias condições de globalização do capitalismo avançado têm gerado uma série de esperanças quanto à democratização da informação. Tais perspectivas desenrolam-se sob um debate pautado na hermenêutica ${ }^{3}$, nas possibilidades de uma ética intercultural da informação como teoria crítica

3 Segundo Rafael Capurro (2003) a palavra hermenêutica, derivada do grego hermeneuein e de significado interpretar, configura-se em um método de grande valia à ciência da informação, na medida em que se baliza na busca de uma verdade histórica sempre aberta e 
emancipatória, levando em conta as distintas identidades políticas e culturais espalhadas pelo mundo e relegadas durante a modernidade, que neste momento poderiam superar a condição de isolamento e invisibilidade. Porém, vale a ressalva de que, no modo de produção capitalista, a celebração das diferenças culturais tem uma ligação muito maior com as próprias necessidades dos "negócios" do que com uma suposta ideia de alcance da informação (produção/acesso) para todos (DANTAS, 2000).

Como coloca Schneider (2015, p.119), sobre a informação submetida ao modo de produção capitalista, operada predominantemente pelas TICs, deve-se sempre atentar para o seu caráter fetichista:

O termo fetichismo, aqui, deve ser entendido em sua mais ampla acepção, a saber, enquanto denominação do processo histórico de subsunção da cultura ao princípio de valorização do valor e ao mesmo tempo de reprodução ideológica e fixação libidinal, processo triplamente funcional, que obtém amplo sucesso em adequar as representações, 0 imaginário e as sensibilidades sociais às necessidades de reprodução ampliada do capital.

Assim frisamos a necessidade de problematizarmos o fenômeno da informação, principalmente enquanto atrelada à moral do capital, de modo que o debate sobre as possibilidades de uma informação para emancipação ou para a cidadania ampliada - com um mundo regido pela ética, pelo bem de fato - passe, antes, pela elaboração profundamente crítica sobre as condições extremamente violentas da produção informacional, enquanto processo de expropriação submetida ao capitalismo e à globalização neoliberal.

No seio de um projeto econômico organizado pelo capital financeiro, o sistema global de informação com hegemonia das tecnologias digitais, ao invés de produzir o bem, tem descambado para a terceirização, a espoliação da força produtiva, o rentismo de organismos financeiros, a fragmentação e efemeridade da vida social e a imposição do neoliberalismo em todas as esferas da existência, contribuído, paulatinamente, para "tratorar" os laços de solidariedade e as formas tradicionais de organização e de resistência.

Logo, percebemos a imensa dificuldade quanto à organização de uma resistência efetiva, capaz de fazer frente ao poderio disciplinador e monopolizador do sistema financeiro global, com consequências violentas não apenas no terreno econômico, mas também na produção intelectual e cultural (DEMUNER, 2017).

Isso não quer dizer que exista um caminho único e destino certo para a informação, pautados pelo capital. Em todo o mundo, fazem-se presentes lutas históricas que descortinam o movimento das contradições. Em uma concepção dialética da realidade, olhar para o fenômeno da globalização neoliberal, conduzido de cima para baixo, é também estar atento para projetos alternativos de informação, organização social e resistência, pautados em uma ética do comum e não na moral das classes dominantes.

\section{Informação, ética e liberdade: ou uma conclusão de esperança}

Recuperando a obra de Marx, Alessandro Baratta (1995) considera que um momento determinante sobre sua visão de homem e de sociedade está em sua concepção das necessidades. Como explica Baratta, ao retomar e desenvolver a posição hegeliana, Marx elabora a dimensão histórica e social de uma teoria das necessidades sem se descuidar da dimensão própria de uma antropologia fundamental. Em Marx, estas duas dimensões se encontram no conceito de trabalho: 
Do ponto de vista da antropologia fundamental, a necessidade não é considerada por Marx no sentido negativo de "carência", mas no sentido positivo de realizar as próprias capacidades e de objetivar-se na relação com a natureza e com os outros homens. O trabalho, entendido como transformação da natureza e como produção, não é, como dizia Marx nos seus primórdios, um meio para satisfazer as necessidades, mas sim a necessidade primária do homem. Por isso, o dever ser é entendido como potencialidade inerente ao ser. [...] Não obstante, a dimensão antropológica se cumpre na dimensão histórica e social. De fato, para Marx, a interação com a natureza não é obra do indivíduo isolado, mas sim dos homens associados na produção de bens não existentes em forma natural. É com a interação produtiva que a história natural das espécies transforma-se na história da sociedade. Com a linguagem, que é condicionada pela interação e que, por sua vez, a condiciona, inicia-se a história da cultura. (BARATTA, 1995, p. 118, 119)

Apesar de uma série de acusações ao marxismo, principalmente quanto a um suposto determinismo sobre o papel da economia na organização das relações sociais, podemos dizer que a formulação de Marx apresentada na citação acima inaugura, na filosofia, os preceitos de uma dialética ontologicamente histórica, redesenhando uma série de discussões quanto à relação dos homens com suas histórias, mas também dos homens consigo mesmos.

Conforme Alves (2010, p. 2), a concepção marxiana de sujeito se recusa a determiná-lo apenas na/pela história, mas tem como fundamental o seu caráter de transformador da história, sendo a práxis a forma por excelência dessa relação (ALVES, 2010, p. 2). Ou seja, a compreensão dialética da realidade quer dizer que as partes estão em permanente relação de interação entre si e com o todo, mas também que o todo não pode ser congelado como abstração situada por cima das partes, visto que o todo cria a si mesmo nas interações das partes (KOSIK, 1978, p. 34).

O que tal reflexão nos apresenta é uma lição emancipatória do marxismo. Como defende Baratta (1995, p. 127), "trata-se de produzir uma operação, com respeito à obra de Marx, que deixa o espaço necessário para as opções e para a responsabilidade do sujeito, sem renunciar à análise radical da realidade"; superando, ao mesmo tempo, as contraposições formuladas pelo positivismo entre sujeito e objeto, ego e mundo, espírito e matéria, razão e paixão, entendendo por paixão, o movimento das necessidades, das pulsões, no qual a história do homem, da sociedade e da cultura, encontra sua continuidade na história da natureza (BARATTA, 1995, p. 120).

A partir da dialética materialista, parece-nos imprescindível pensarmos na informação, fundamentalmente, como produto histórico, ou seja, localizado no tempo e no espaço, mas nascido da intervenção do ser humano no mundo e, por isso, em permanente movimento e disputa (MARX, 1993).

Como observa Sodré (1995, p.56),

o empenho é colocar o indivíduo livre frente às afecções que o tiranizam. Porém, a liberdade não é uma idiotia, uma ação de singularidade ilimitada, mas a expressão de um singular que se admite regido por forças delimitantes, por marcas da comunidade, de grupo. Liberdade é assim, o empenho que se tem em viver. A liberdade faz-se quase sempre contra a metafísica, introjetada na consciência do sujeito. A crítica radical da metafísica faz aparecer, de uma maneira ou de outra, a ética. Quando Marx critica a metafísica do valor entronizada pela economia política burguesa, desenha-se no horizonte do sujeito a revolução como um imperativo ético.

A lição está, justamente, em uma luta pela desmistificação da falsa liberdade, ou ao aspecto estático das instituições que constroem um "bem de direito" para apenas uma parte da sociedade, dando lugar a uma possibilidade ética em que a informação esteja a serviço do bem universal de fato, com abertura para a historicidade, novas possibilidades e rupturas. Ou seja, a informação a serviço da verdadeira liberdade e da emancipação humana. 


\section{Referências}

ALVES, Alvaro. O método materialista histórico dialético: alguns apontamentos sobre a subjetividade. In: Revista de Psicologia da UNESP, v.9, n.1, 2010.

ARANTES, Pedro. O ajuste urbano: as políticas do Banco Mundial e do BID para as cidades. In: pós, n.20, São Paulo, 2006.

ARAúJo, Carlos Alberto Ávila. A ciência da Informação como ciência social. In: Ci. Inf., v. 32, n. 3, Brasília, 2003.

BARATTA, Alessandro. Ética e pós-modernidade. In: KOSOVSKI, Ester (Org.). Ética na comunicação. Rio de Janeiro: Mauad, 1995.

BATISTA, William. Ética e contemporaneidade: sujeito e destruição do destino. In: KOSOVSKI, Ester (Org.). Ética na comunicação. Rio de Janeiro: Mauad, 1995.

BEZERRA, Arthur; SALDANHA, Gustavo. Sobre Comte, Durkheim e Tarde em Otlet: o papel do positivismo na consolidação dos estudos da informação. In: ALBAGLI, Sarita (org). Fronteiras da Ciência da Informação. Brasilia: IBICT, 2013.

BOURDIEU, Pierre. O campo científico. In: ORTIZ, Renato (Org.). A sociologia de Pierre Bourdieu. São Paulo: Ática, 1994.

Sobre as artimanhas da razão imperialista. In: Estudos Afro-Asiáticos, vol 24, no1, 2002.

CAPURRO, Rafael. Epistemologia e ciência da informação. In: ENCONTRO NACIONAL DE PESQUISA EM CIÊNCIA DA INFORMAÇÃO - ENANCIB, 2003. Belo Horizonte. Anais. Belo Horizonte: UFMG, 2003.

Prólogo. In: SCHNEIDER, Marco. A dialética do gosto: informação, música e política. Rio de Janeiro: Editora Circuito, 2015.

DANTAS, Marcos. Prefácio. In: BOLAÑO, César. Indústria Cultural, informação e capitalismo. São Paulo: Editora Hucitec/ Editora Pólis, 2000.

DEMUNER, Davi. O movimento zapatista e a solidariedade de classe transnacional: uma análise da luta de classes na globalização. Dissertação (mestrado em relações internacionais). Instituto de Economia e Relações Internacionais da Universidade Federal de Uberlândia, Uberlândia, 2017.

GRAMSCI, António. Maquiavel, a Política e o Estado Moderno. Rio de Janeiro: Civilização Brasileira, 1984.

HARVEY, David. Espaços de esperança. São Paulo: Edições Loyola, 2004.

HOBSBAWM, Eric. Era dos Extremos: o breve século XX : 1914-1991. São Paulo : Companhia das Letras, 1995.

KOSIK, Karel. Dialética do concreto. Rio de Janeiro: Paz e Terra, 1976.

MARX, Karl. Manuscritos econômicos-filosóficos. Lisboa: Edições 70, 1993.

MENDONÇA, Sonia Regina de. Estado, Violência Simbólica e Metaforização da Cidadania. Revista Tempo, Rio de Janeiro, vol 1, 1996.

MÉSZÁROS, István. O Poder da ideologia. São Paulo: Boitempo, 2007.

MORAES, Denis. Mídia e globalização neoliberal. In: Revista Univerciencia, vol 7, no, 2002.

RIOS, Terezinha. A ética na pesquisa e a epistemologia do pesquisador. Psicol. rev. (Belo Horizonte) v. 12 n.19 Belo Horizonte jun. 2006

SCHNEIDER, Marco. A dialética do gosto: informação, música e política. Rio de Janeiro: Editora Circuito, 2015. - BEZERRA, Arthur; CASTRO, Leonardo. Contribuições de Pierre Bourdieu para um esboço de autoanálise da Ciência da Informação. In: MARTELETO, Regina; PIMENTA, Ricardo (orgs). Pierre Bourdieu e a produção social da cultura, do conhecimento e da informação. Rio de Janeiro: Garamond, 2017.

SODRÉ, Muniz. Ética, política e psicanálise. In: KOSOVSKI, Ester (Org.). Ética na comunicação. Rio de Janeiro: Mauad, 1995.

THOMPSON, Edward P. Foldore, antropologia e história social. In: A. L. Negro \& S. Silva (Org.). As peculiaridades dos ingleses e outros artigos. Campinas: editora da Unicamp, 2001. 